\title{
Rancang Bangun Website yang Berorientasi Video Sebagai Sarana Media Informasi di SMK YP 17-2 Malang
}

\author{
Iis Sholikhat ${ }^{1,}$, Hudan Eka Rosyadi ${ }^{2}$, Devita Maulina Putri ${ }^{3}$ \\ Fakultas Teknologi Informasi, Universitas Merdeka Malang, Indonesia \\ ${ }^{1}$ iis.sholikhat@gmail.com, ${ }^{2}$ hudan@ unmer.ac.id, ${ }^{3}$ devitamaulinaputri@gmail.com \\ * corresponding author
}

ARTIKEL INFO

Article history

Diterima: 13 Juni 2019

Direvisi: 3 Juli 2019

Diterbitkan: 30 Agustus 2019

\section{ABSTRAK}

Website memiliki peranan penting sebagai media yang tidak memiliki batas ruang dan waktu, khususnya di bidang pendidikan. Sehingga masyarakat dengan mudah mengetahui informasi mengenai sekolah yang akan dituju. Setelah penulis melakukan survei, pengumpulan data dan wawancara, penulis memilih Sekolah Menengah Kejuruan YP 17-2 Malang. Karena sekolah ini belum memiliki website dan memiliki potensi yang baik kedepannya, maka dari itu penulis merancang sebuah website untuk menerapkan sistem pendidikan berbasis teknologi informasi dan komunikasi. Metode yang digunakan penulis dalam penelitian ini yaitu dengan melakukan identifikasi isu/topik, pengumpulan data, pengolahan data, perancangan desain website dan dilanjutkan dengan pembangunan website yang berorientasi video. Hasil dari penelitian ini adalah menghasilkan sebuah website Sekolah Menengah Kejuruan YP 17-2 Malang yang berorientasi video sehingga dapat mempermudah masyarakat umum memperoleh informasi yang menarik dari sekolah ini. Website ini juga akan memberikan banyak manfaat dengan memanfaatkan media ini untuk memperkenalkan dan mempromosikan sekolah pada masyarakat umum, agar segala informasi yang berkaitan dengan sekolah dapat diketahui oleh masyarakat serta mampu menambah potensi bagi media informasi sekolah.

\section{PENDAHULUAN}

Website memiliki peranan penting sebagai media dengan jaringan terluas di dunia yang tidak memiliki batas wktu dan melampaui batas wilayah. Saat ini website dalam bidang pendidikan mendapatkan perhatian khusus dan tanggapan yang sangat bagus dari berbagai pihak baik tenaga pendidikan, siswa serta masyarakat [1]. Dengan website khususnya dalam bidang pendidikan semua pihak dapat merasakan manfaat yakni dapat mengenal lingkup sekolah lebih mendalam. Media video merupakan media perantara atau penggunaan materi yang penyerapannya melalui pandangan dan pendengaran sehingga membangun kondisi yang dapat membuat pembaca mampu memahami informasi yang disampaikan [2]. Dengan media video sebagai sarana informasi masyarakat umum lebih tertarik untuk mengetahui kelebihan atau kualitas yang dimiliki sekolah. Menurut penelitian awal yang penulis lakukan, Sekolah Menengah Kejuruan YP 17-2 Malang merupakan sekolah yang didirikan tahun 1992, namun hingga saat ini belum memiliki website resmi sehingga kurang adanya media untuk penyampaian informasi. Saat ini media informasi hanya berupa blog dan brosur. Maka dari itu penulis merancang sebuah website untuk menerapkan sistem pendidikan berbasis teknologi informasi dan komunikasi. Website ini juga akan memberikan banyak manfaat dengan memanfaatkan media ini untuk memperkenalkan dan mempromosikan sekolah pada masyarakat umum, agar segala informasi yang berkaitan dengan sekolah dapat diketahui oleh masyarakat serta mampu menambah potensi bagi 
media informasi sekolah. Oleh karena itu penulis mengimplementasikan media video ke dalam website sebagai sarana informasi untuk memperkenalkan profil Sekolah Menengah Kejuruan YP 17-2 Malang [3][4]. Permasalahan Sekolah Menengah Kejuruan YP 17-2 Malang ini adalah kurangnya pemanfaatan dalam proses promosi melalui media video dimana nantinya untuk menunjang peningkatan citra bagi sekolah tersebut. Dengan melihat permasalahan tersebut, bagaimana penerapan media video melalui website untuk meningkatkan dan mempromosikan di Sekolah Menengah Kejuruan YP 17-2 Malang. Tujuan dan manfaat dari penelitian adalah untuk menerapkan media video melalui website untuk meningkatkan, mempromosikan dan sekaligus memperkenalkan segala informasi yang berkaitan di Sekolah Menengah Kejuruan YP 17-2 Malang, yang nantinya mampu menambah citra dari sekolah tersebut di khalayak masyarakat.

\section{METODE}

Metode penelitian menggunakan metode pengumpulan data diantaranya yaitu studi pustaka, observasi, wawancara dan metode dokumentasi. Proses wawancara penulis melakukan tanya jawab secara langsung terhadap narasumber [5]. Metode dokumentasi berupa pengambilan data informasi sekolah, video, gambar [6]. Data informasi sekolah yang dimaksud merupakan segala keterangan mengenai hal yang berkaitan dengan pembuatan website sekolah [7][8]. Pengolahan data yang penulis gunakan berupa editing yang mengarah pada proses editing video dari hasil dokumenasi dan coding yang mengarah pada proses pengkodean dalam pembuatan website sekolah [9][10]. Lokasi penelitian yang penulis lakukan bertempat di SMK YP 17-2 Malang Jalan Melati Utara No.65 Malang. Tujuan utama penelitian ini untuk membuat informasi tentang SMK YP 172 malang dengan menggunakan teknologi informasi berbasis website sehingga dapat bermanfaat bagi masyarakat umum dan sekolah pada umumnya. Adapun struktur tahapan penelitian yang penulis lakukan dalam melakukan penelitian adalah sebagaimana Gambar 1.

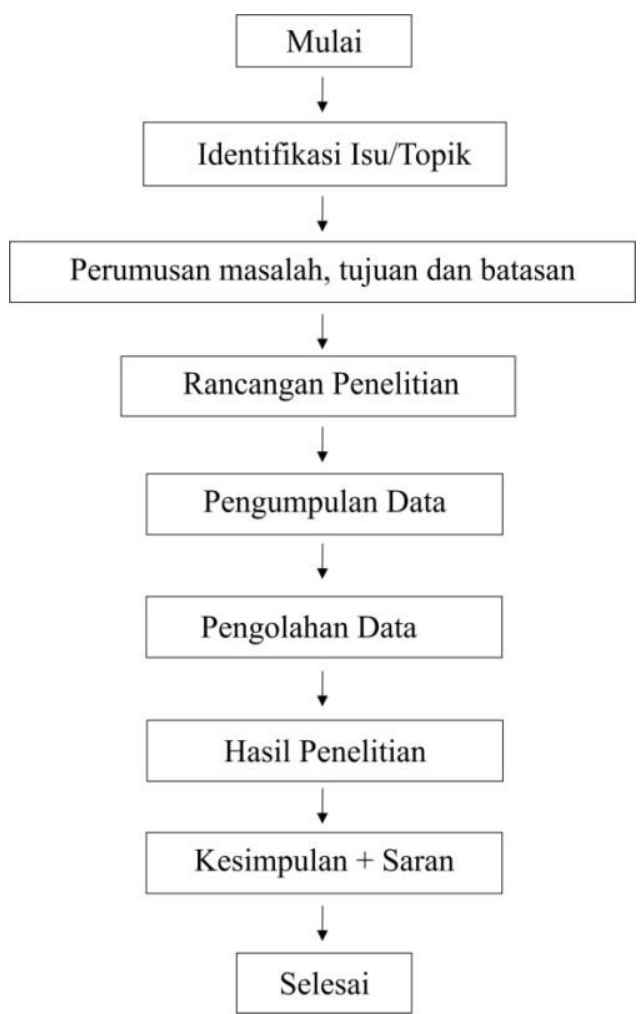

Gambar 1. Struktur Tahapan Penelitian 


\section{Use Case Diagram}

\section{PEMBAHASAN}

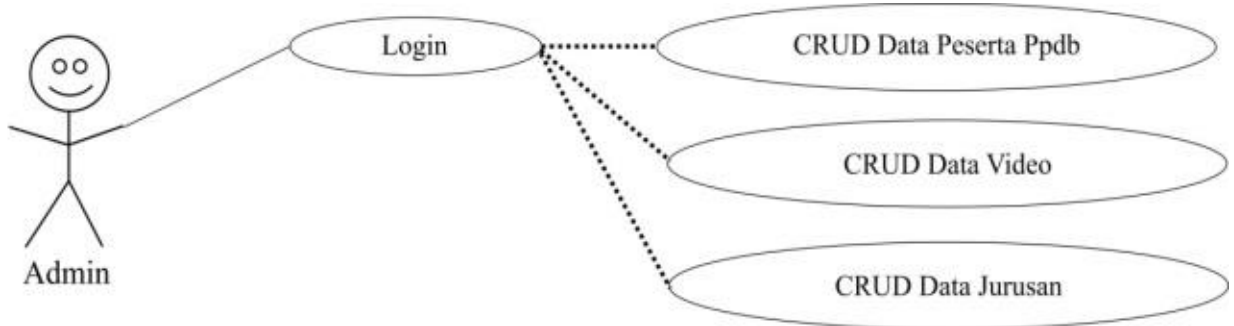

Gambar 2. Use Case Diagram Admin

Tabel 1. Definisi Use Case Admin

\begin{tabular}{|l|l|l|}
\hline No & \multicolumn{1}{|c|}{ Use Case } & \multicolumn{1}{c|}{ Deskripsi } \\
\hline 1. & Login. & $\begin{array}{l}\text { Merupakan proses awal utuk menuju halaman administrator, pada } \\
\text { proses login ini yang berhak mengkases yaitu admin. }\end{array}$ \\
\hline 2. & CRUD Data PPDB. & $\begin{array}{l}\text { Merupakan proses pengubahan, penambahan dan penghapusan data } \\
\text { peserta ppdb yang dilakukan oleh admin. }\end{array}$ \\
\hline 3. & CRUD Data Jurusan. & $\begin{array}{l}\text { Merupakan proses penambahan, pengubahan, penghapusan data } \\
\text { jurusan. }\end{array}$ \\
\hline 4. & CRUD Data Video. & Merupakan proses penambahan, penghapusan data video. \\
\hline
\end{tabular}

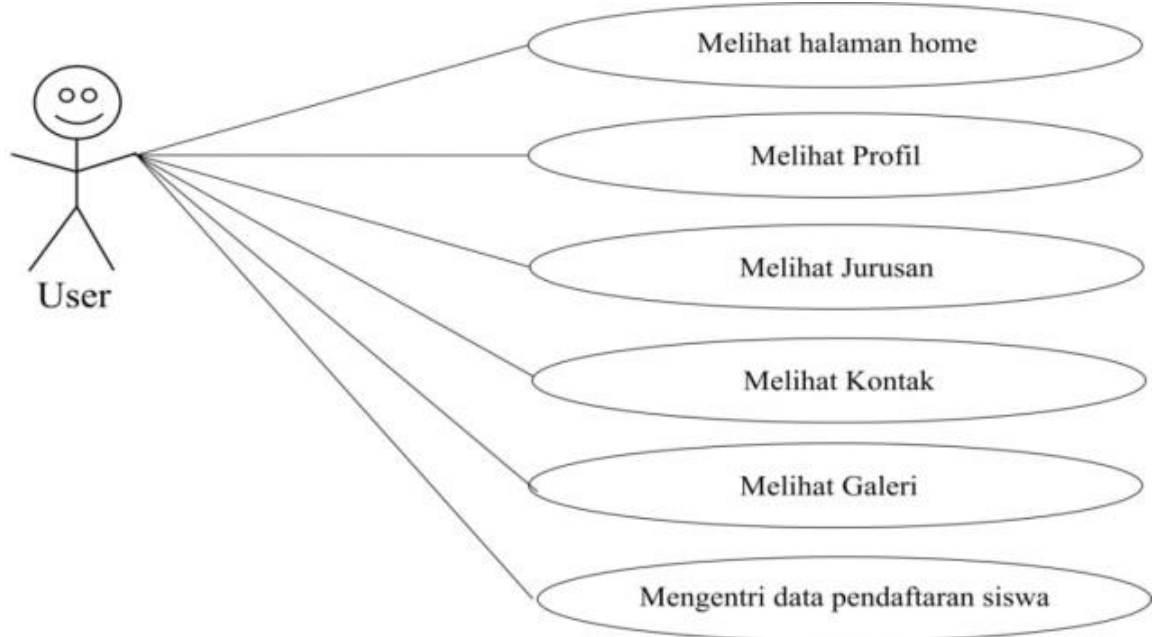

Gambar 3. Use Case Diagram User

Tabel 2. Definisi Use Case User

\begin{tabular}{|l|l|l|}
\hline No & \multicolumn{1}{|c|}{ Use Case } & \multicolumn{1}{|c|}{ Deskripsi } \\
\hline 1. & Melihat halaman home. & Merupakan proses menampilkan konten menu home. \\
\hline 2. & Melihat Profil. & $\begin{array}{l}\text { Merupakan proses menampilkan konten menu untuk melihat } \\
\text { informasi profil yang ada di SMK YP 17-2 Malang }\end{array}$ \\
\hline 3. & Melihat Jurusan. & $\begin{array}{l}\text { Merupakan proses menampilkan menu untuk melihat informasi } \\
\text { jurusan yang ada di sekolah. }\end{array}$ \\
\hline 4. & Melihat Galeri. & Merupakan proses menampilkan galeri foto dan video. \\
\hline 5. & Melihat Kontak. & $\begin{array}{l}\text { Merupakan proses menampilkan informasi kontak yang bisa } \\
\text { dihubungi di sekolah. }\end{array}$ \\
\hline 6. & $\begin{array}{l}\text { Mengentri } \\
\text { pendaftaran online. }\end{array}$ & $\begin{array}{l}\text { Merupakan proses dimana user yang ingin mendaftar memasukkan } \\
\text { data keperluan data untuk pendaftaran. }\end{array}$ \\
\hline
\end{tabular}


Pembuatan website sekolah ini menggunakan database MySql sebagai media penyimpanan data. Adapun tabel-tabelnya sebagai berikut.

Tabel 3. Login Admin

\begin{tabular}{|l|l|}
\hline \multicolumn{1}{|c|}{ Nama Field } & \multicolumn{1}{c|}{ Type } \\
\hline Id* $^{*}$ & Int (10) \\
\hline Nama & Varchar (100) \\
\hline Username & Varchar (100) \\
\hline Password & Varchar (100) \\
\hline
\end{tabular}

Tabel 4. Ppdb Online

\begin{tabular}{|l|l|}
\hline \multicolumn{1}{|c|}{ Nama Field } & \multicolumn{1}{c|}{ Type } \\
\hline Id_Calon & Int (11) \\
\hline Id_Jurusan & Int(1) \\
\hline Nama_Calon & Varchar(200) \\
\hline NISN & Varchar(100) \\
\hline Tempat_Lahir & Varchar(20) \\
\hline Nomor_Telepon & Date \\
\hline Tanggal_Lahir & Varchar(50) \\
\hline JK_Calon & Text \\
\hline Agama & Varchar(150) \\
\hline Asal_Sekolah & Float \\
\hline Danun & Text \\
\hline Alamat_Calon & Text \\
\hline Hobi &
\end{tabular}

Tabel 5. Jurusan

\begin{tabular}{|l|l|}
\hline \multicolumn{1}{|c|}{ Nama Field } & \multicolumn{1}{c|}{ Type } \\
\hline Id_Jurusan* & Int (11) \\
\hline Nama_Jurusan & Varchar (100) \\
\hline
\end{tabular}

Tabel 6. Video

\begin{tabular}{|l|l|}
\hline \multicolumn{1}{|c|}{ Nama Field } & \multicolumn{1}{c|}{ Type } \\
\hline Id_VIdeo* & Int (11) \\
\hline Judul_Video & Text \\
\hline Link_Video & Text \\
\hline
\end{tabular}

\section{Hasil Tampilan Website}

\section{Beranda}

Menampilkan informasi mengenai sekilas profil sekolah dalam bentuk video, sambutan kepala sekolah dan beberapa berita atau informasi tentang kegiatan yang berada di sekolah. 


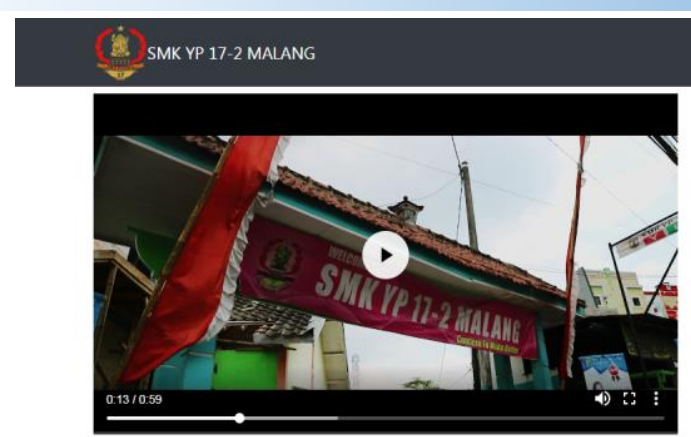

SAMBUTAN KEPALA SEKOLAH

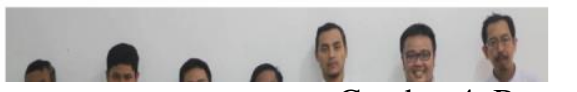

Gambar 4. Beranda
Beranda Profil Junsan Ppodb Galen Kontiak

SMK YP 17-2 MALANG

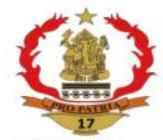

Selamat datang di Website SMKYP 17-2 Malan

Penerimaan siswa baru telah dibuka dengan

jurusan:

1. Teknik Komputer dan Jaringa

2. Rekayasa Perangkat lungk

Pendaftaran:

telah dibuka mulai saat in

Waktu Pendaftara

Senin $s / d$ Sabtu

Pukul $07.00-13.00$ Wie

\section{Profil}

Menampilkan video yang diperankan oleh salah satu perwakilan humas mengenai visi dan misi sekolah serta tujuan sekolah.

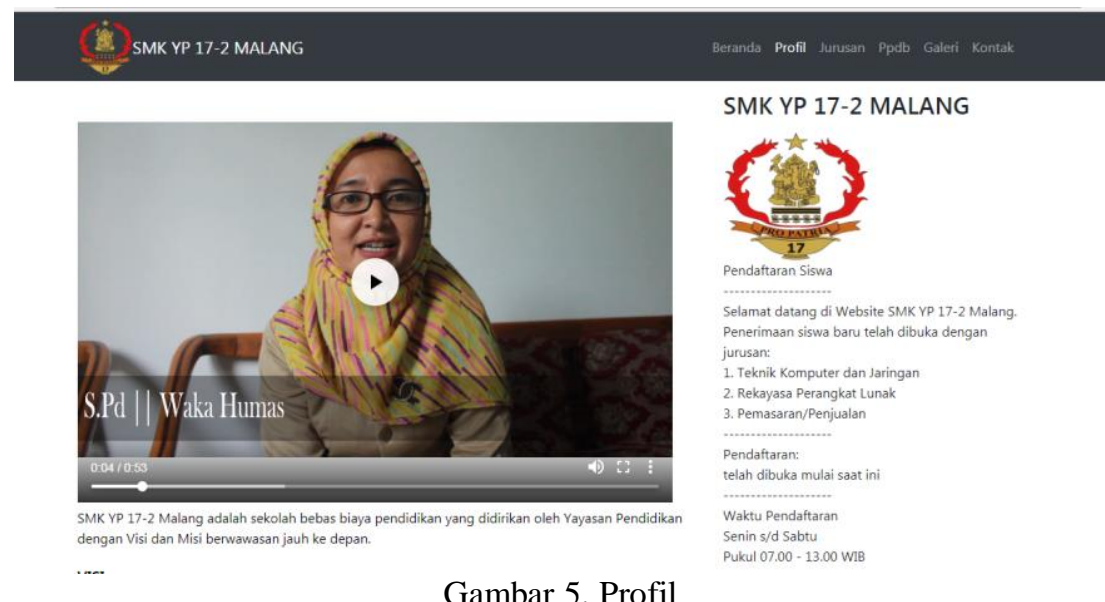

\section{Jurusan}

Menampilkan video salah satu perwakilan guru yang menjelaskan tentang jurusan teknik informasi dan jaringan.

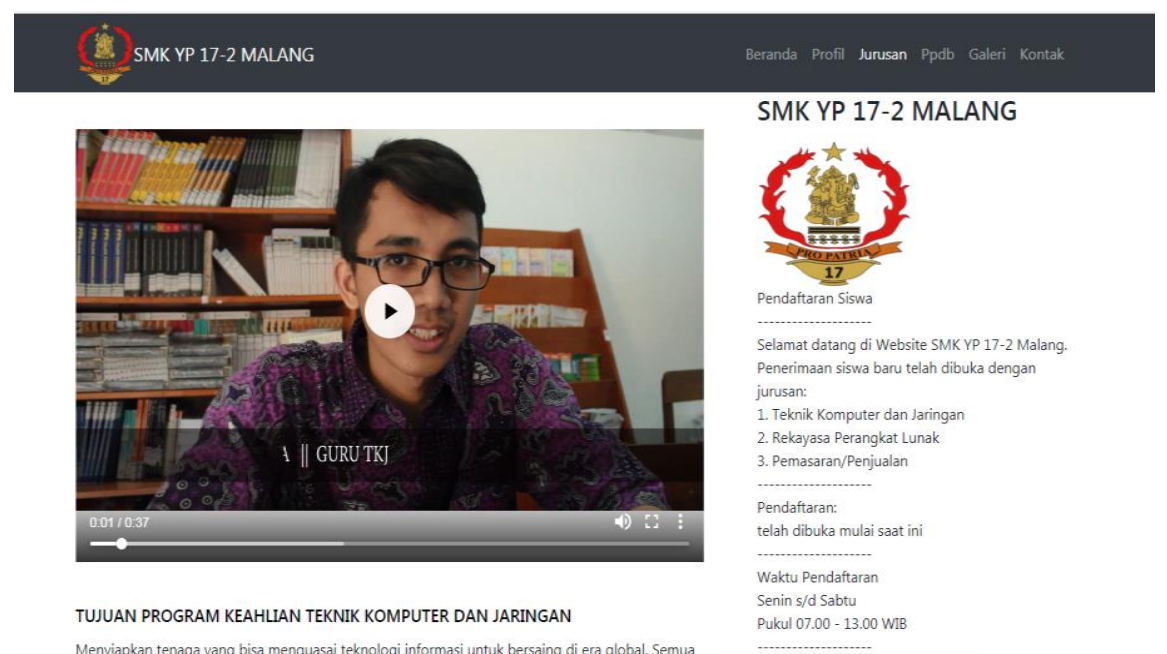

Gambar 6. Jurusan 


\section{Ppdb}

Menampilkan informasi pendaftaran.

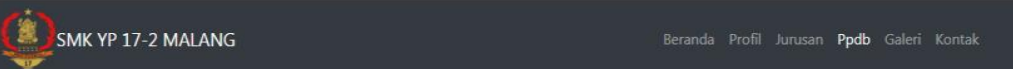

Info Pendaftaran

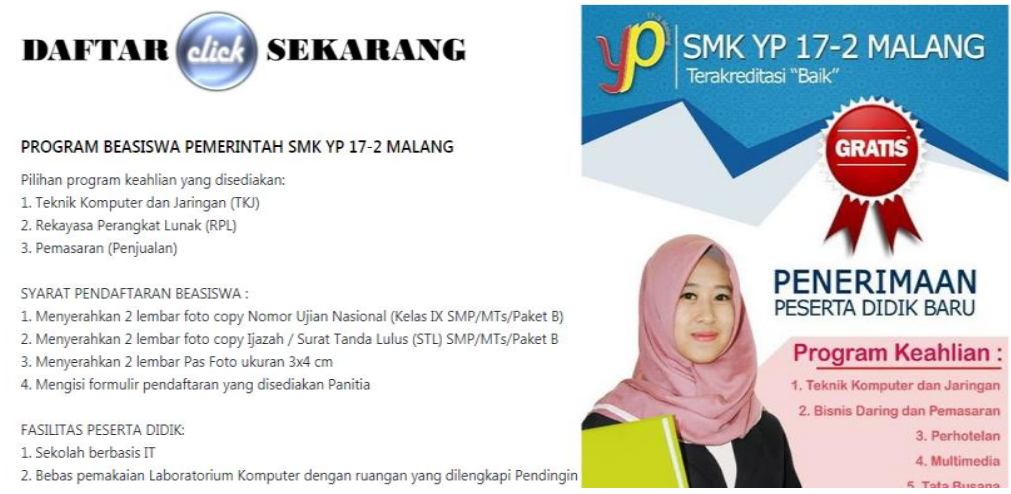

Gambar 7. Ppdb

\section{Form pendaftaran online}

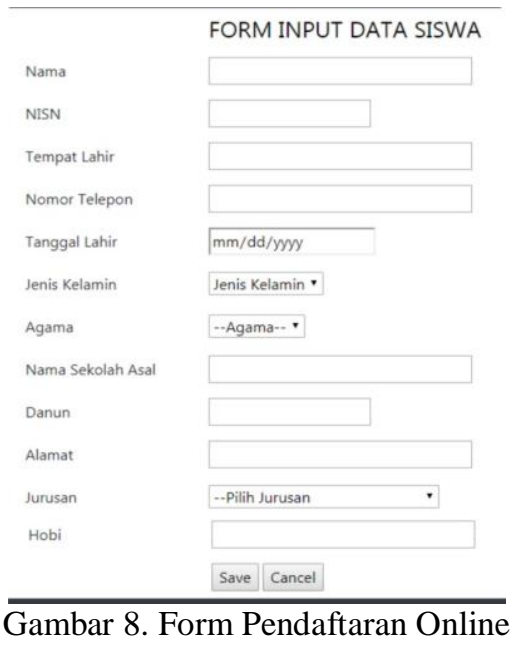

\section{Galeri Foto/Video}

Menampilkan beberapa foto dan video yang terdapat pada sekolah sehingga user mudah mengetahui kondisi atau keadaan sekolah secara tepat dan menarik

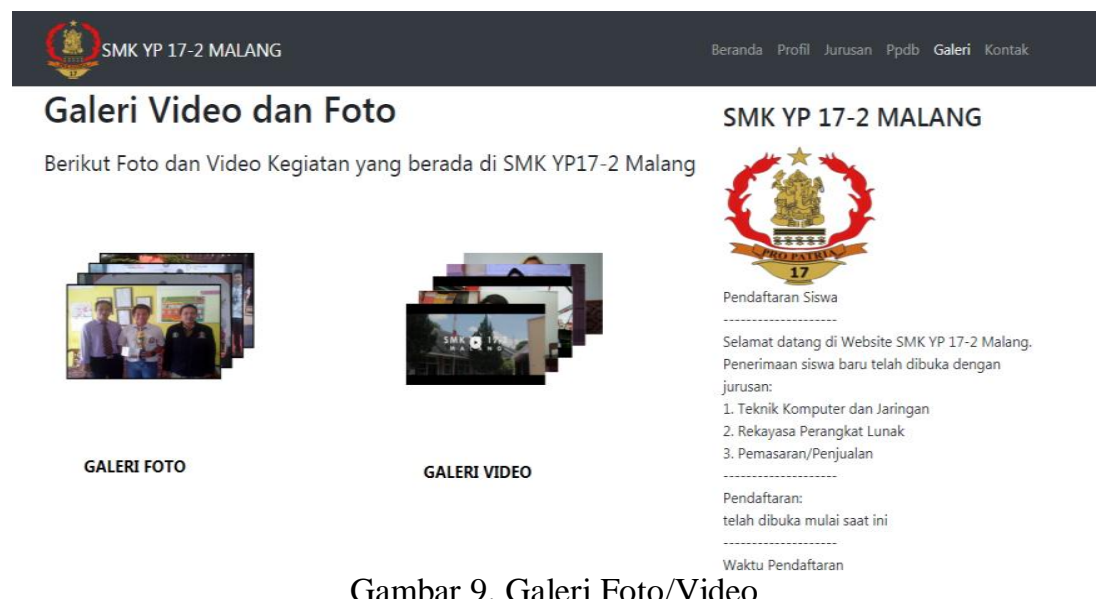

Gambar 9. Galeri Foto/Video 


\section{Kontak}

Menampilkan informasi mengenai lokasi dan kontak yang dapat dihubungi mengenai sekolah. Dalam hal ini mempermudah user mengetahui lokasi dengan tepat.

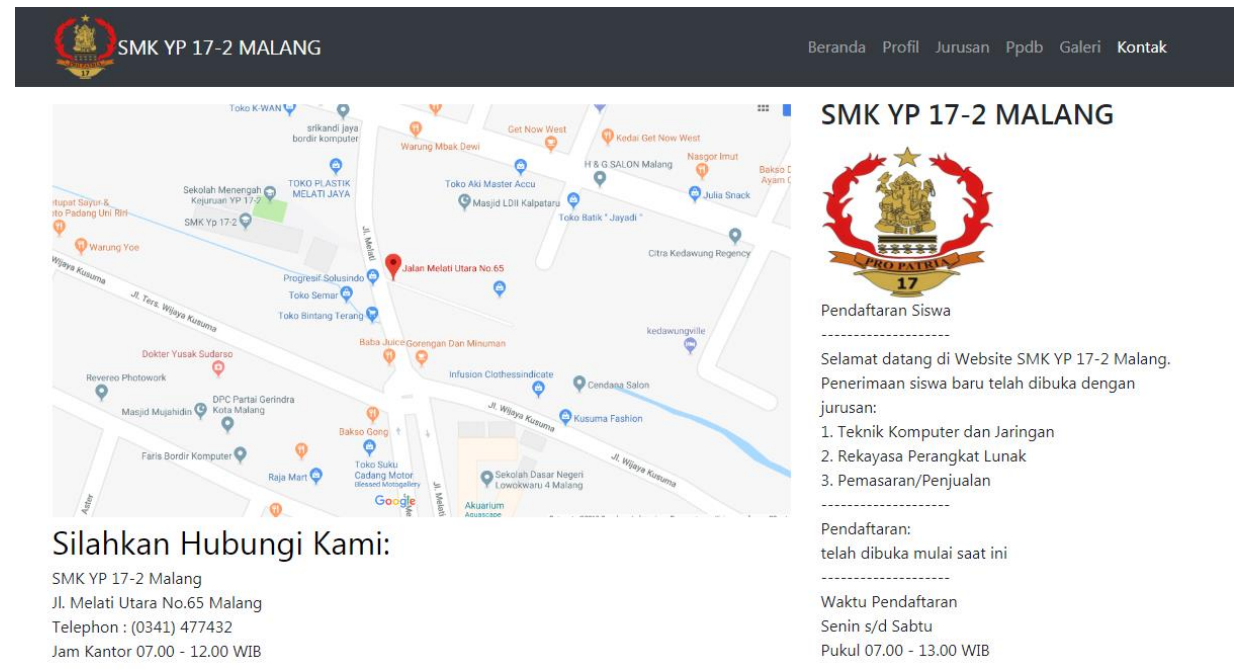

Gambar 10. Kontak

\section{Login Admin}

Proses awal masuk menuju halaman administrator.

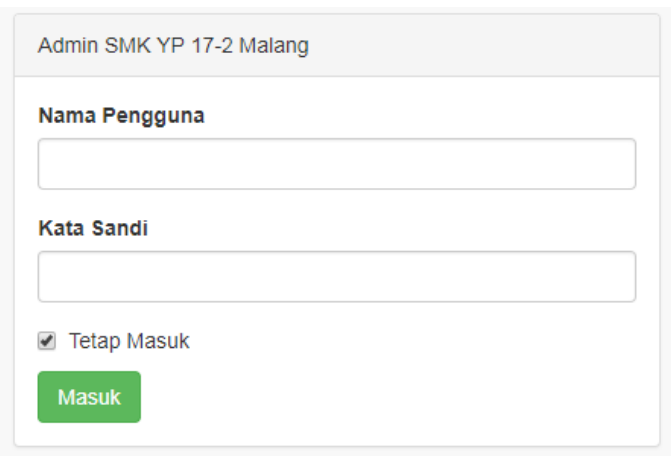

Gambar 11. Login Admin

\section{Halaman Admin}

Halaman utama administrator yang menampilkan beberapa data mengenai jurusan, foto/video dan ppdb.

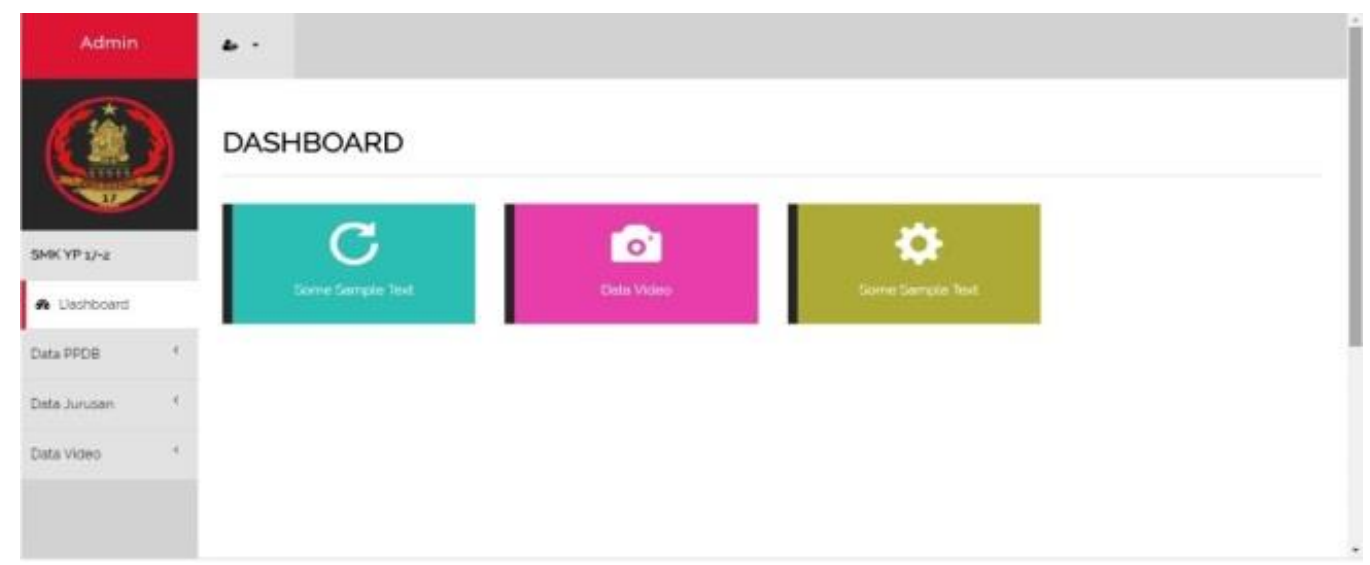

Gambar 12. Halaman Utama Admin 


\section{Data Video / Foto}

Menampilkan data video dan foto.

DATA VIDEO

\begin{tabular}{|c|c|c|c|}
\hline \multicolumn{2}{|c|}{ Tambah Data Baru } & \multicolumn{2}{|l|}{ Cari: } \\
\hline ID VIDEO & JUDUL VIDEO & LINK VIDEO & Tools \\
\hline 25 & kjhkjhkjhkj & humas.mp4 & Hapus \\
\hline 28 & coba1 & murid fix mp4 & Hapus \\
\hline 30 & cover & smkyp_cover.mp4 & Hapus \\
\hline 32 & GURU & gurump4 & Hapus \\
\hline 34 & tiga & 3.jpg & Hapus \\
\hline 35 & empat & 7.jpg & Hapus \\
\hline 36 & dua & 2.jpg & Hapus \\
\hline 37 & satu & 1.jpg & Hapus \\
\hline
\end{tabular}

Gambar 13. Data Video/Foto

\section{Data Jurusan}

Menampilkan data jurusan yang ada di sekolah

\section{TABEL JURUSAN}

\begin{tabular}{|l|l|l|}
\hline \multicolumn{2}{|c|}{ Tambah Data Baru } \\
\hline ID_JURUSAN & NAMA JURUSAN & Tapus \\
\hline 3 & Pemasaran & Hapus \\
\hline 4 & Teknik Komputer dan Jaringan & Hekayasa Perangkat Lunak \\
\hline 5 & kodok ga ngorek & Edit \\
\hline 6 & Hapus \\
\hline
\end{tabular}

Gambar 14. Data Jurusan

\section{Data Ppdb}

Menampilkan data ppdb online yang sudah terdaftar melalui website user.

DATA PPDB

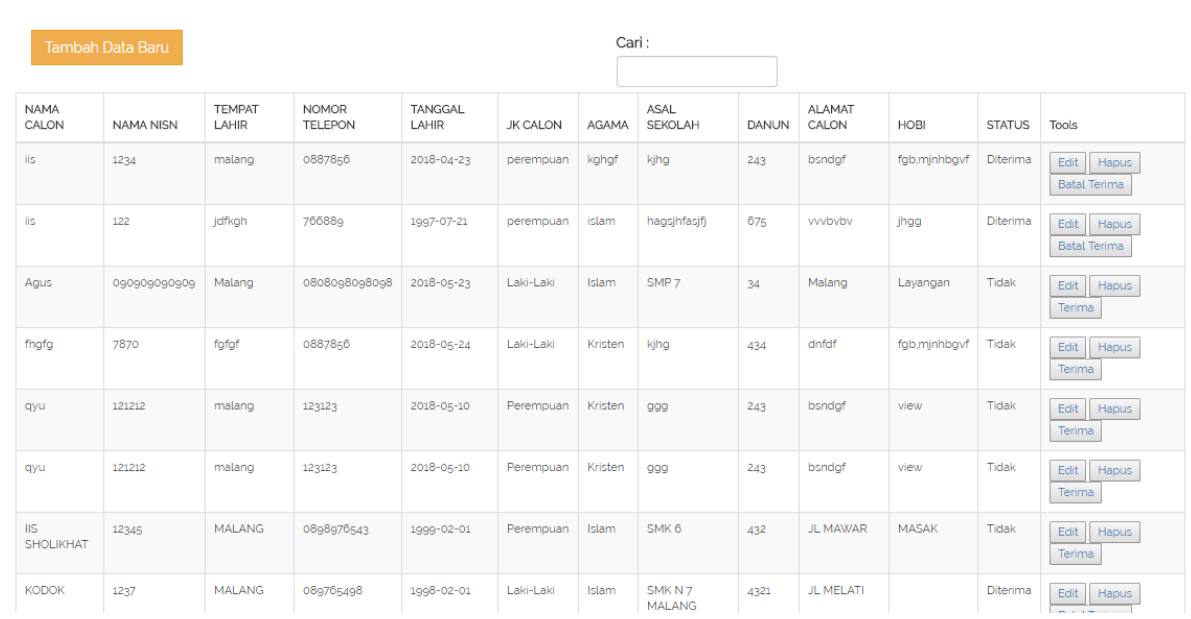

Gambar 15. Data Ppdb 
Dari hasil pembuatan website ini dapat disimpulkan bahwa proses penyebaran informasi melalui website diharapkan dapat secara efektif mempermudah masyarakat khususnya dalam memperoleh informasi antara lain pendaftaran peserta didik baru, mengetahui profil sekolah dan menambah tingkat kepercayaan masyarakat terhadap SMK YP 17-2 Malang.

\section{KESIMPULAN}

Mengacu pada hasil dan pebahasan maka hasil penelitian dapat disimpulkan sebagai berikut. Pertama, perancangan dan pembuatan website memudahkan masyarakat umum untuk memperoleh berbagai informasi yang ada di sekolah. Kedua, website yang penulis bangun telah berhasil menampilkan beberapa info seperti profil, jurusan, galeri foto dan video, pendaftaran online serta video ringkasan mengenai profil sekolah. Mengacu pada simpulan dirumuskan saran-saran sebagai berikut. Pertama, website ini memiliki tampilan yang sangat sederhana pada tampilan admin maupun user, untuk itu tahap pengembangan diharapkan dapat dibuat semenarik mungkin dan dikembangkan lebih lanjut dengan menambahkan informasi yang lebih akurat. Kedua, konten berita pada beranda masih menggunakan website statis, maka dari itu diharapkan untuk dikembangkan lebih lanjut agar memudahkan admin untuk memberi berita terbaru di sekolah.

\section{REFERENSI}

[1] Anissatul Mufarokah. 2009. Srategi Belajar Mengajar (Yogyakarta: TERAS,2009), h.104.

[2] Arief, Rudyanto. 2010. Implementasi Constraint untuk Menjamin Konsistensi dan Integritas Data Dalam Database.pdf, Jurnal Dasi Vol.11 No. 2, media.neliti.com

[3] Handayani, Heni. 2014. Xampp.pdf, ilmuti.org

[4] Hartono, Hamzah. 2014. Pengertian Website dan Fungsinya.pdf, ilmuti.org

[5] Kadir, Abdul. 2008. Dasar Pemrograman Web Dinamis Menggunakan PHP / Abdul Kadir; - Ed.III. Yogyakarta:ANDI

[6] Pamuji, Sugeng. 2013. Pembuatan Website Sebagai Media Informasi dan Promosi pada Sekolah Menengah Kejuruan (SMK) Muhammadiyah 4 Wonogiri.pdf, Surakarta, epub.tiunsa.org

[7] Pribadi, Benny Agus. 204. Materi Pokok Media Teknologi. Jakarta: Universitas Terbuka.

[8] Suhartanto, Medi. 2102. Pembuatan Website Sekolah Menengah Pertama Negeri 3 Delanggu dengan Menggunakan PHP dan MySQL.pdf. Journal Speed, ijns.org

[9] Supriatini. 2017. Penerapan Media Audio Visual dalam Meningkatkan Keterampilan Menulis Puisi Siswa Kelas VII SMP Negeri 13 Palembang. Jurnal Bindo Sastra 1(1) (2017).

[10] Wardany, Widya. 2012. Pembuatan Website Profil Sekolah Menengah Pertama Negeri 1 Jaten Karanganyar, journal.ijns.org, ISSN: 2302-1136 